\title{
Supplementary material to "Surface ozone in the southern hemisphere: 20 years of data from a site with a unique setting in El Tololo, Chile" by Anet et al.
}

\section{S1: Comparison between TECO 49 (DMC) and TE49C (Empa)}

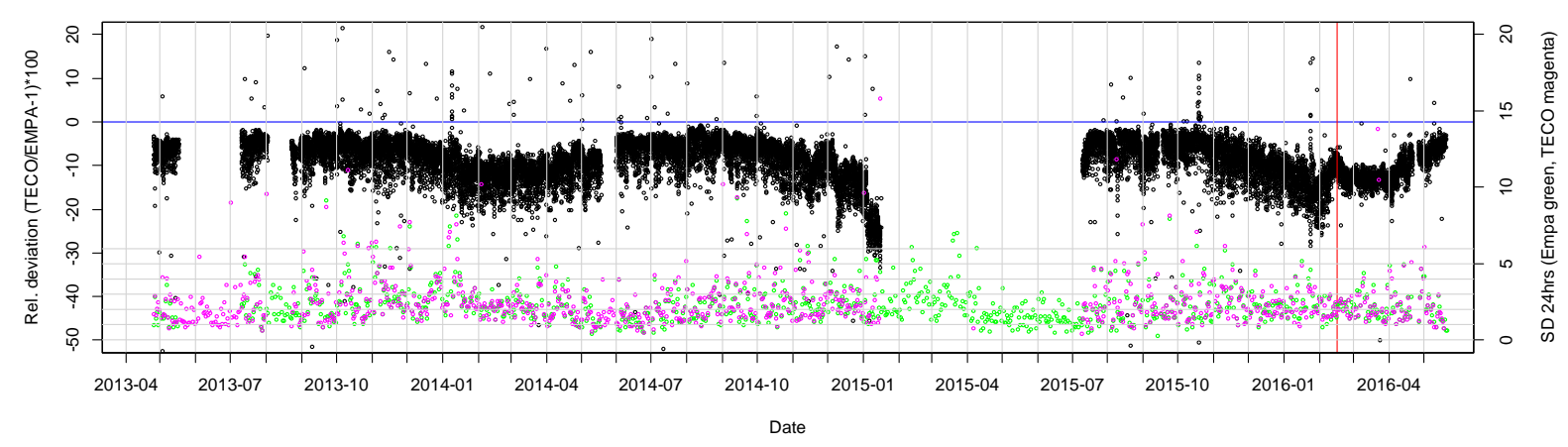

Fig. S1: Relative deviation of ozone measurements between TECO 49 and TE49C. Negative values (below blue line) show higher values measured with TE49C. Coloured points illustrate the 1-day standard deviation of measurements done either with the TECO 49 (magenta) or TE49C (green). Red line shows the time when the inlet tubing of the TECO 49 was replaced.

Since late April 2013, ozone at TLL has been measured in parallel with the TECO 49 from DMC and with a TE49C installed by Empa. Already in the beginning, a slight offset of 8-10\% was noticed (equivalent to 2-3 ppb during average conditions at TLL). A more in-depth analysis revealed an annual cycle of the relative deviation ranging between 5 and $15 \%$ (equivalent to around 2 and $4 \mathrm{ppb}$ ) with the TECO 49 device always measuring less ozone than the TE49C. From mid-January 2015 to mid-June 2015, a series of failures interrupted the measurements of the TECO 49.

In late January 2016, the inlet tubing of the TECO 49 inlet was replaced, as it was speculated that the low readings were due to ozone losses at the inner surfaces of the aged (and possibly slightly soiled) tubing. No change in the differences could be observed after the change of the inlet tubing indicating that the aging of the tubing did not cause the losses and progressively growing losses over the years are unlikely. Presumably, the small systematic offset is due to different inlet heights above ground and the different exposure of the intakes. The intake of the inlet for the TECO 49 is $2 \mathrm{~m}$ above ground whole the TE49C intake is at $5 \mathrm{~m}$ above ground. 


\section{S2: Filtering example}
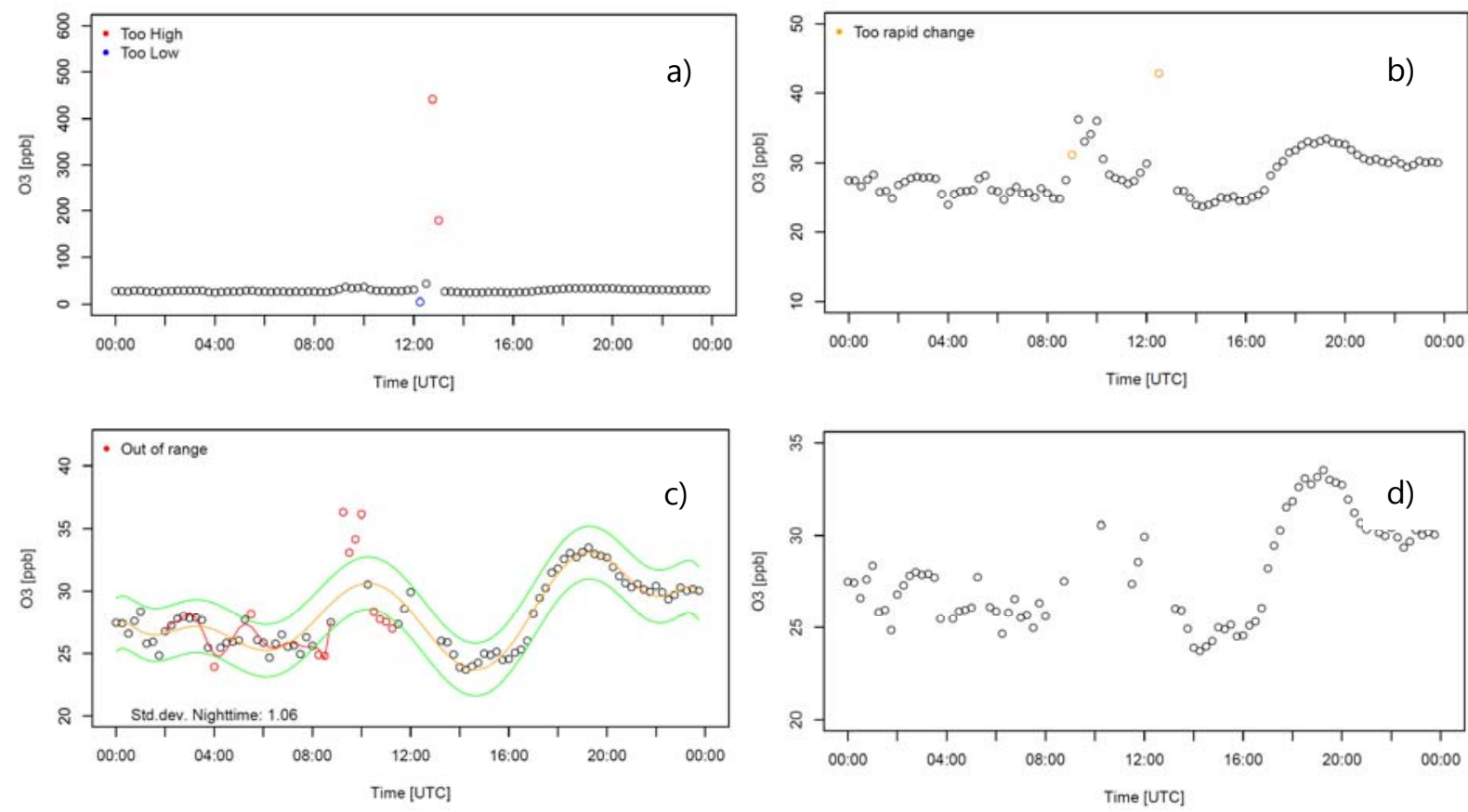

Fig. S2: Example of a typical filtering sequence, using original TECO 49 data from El Tololo between January 10th 2015 and January 11th 2015, UTC times. In a to d, the different steps are illustrated: a) Filtering out too high (red) and too low values (blue), b) Filtering too rapid changes (orange), c) Filtering out values exceeding twice the standard deviation (green curve, red points) computed over the polynomial fit during nighttime (23 to 6 LT, red curve), d) Final result. 


\section{S3: Additional figures}

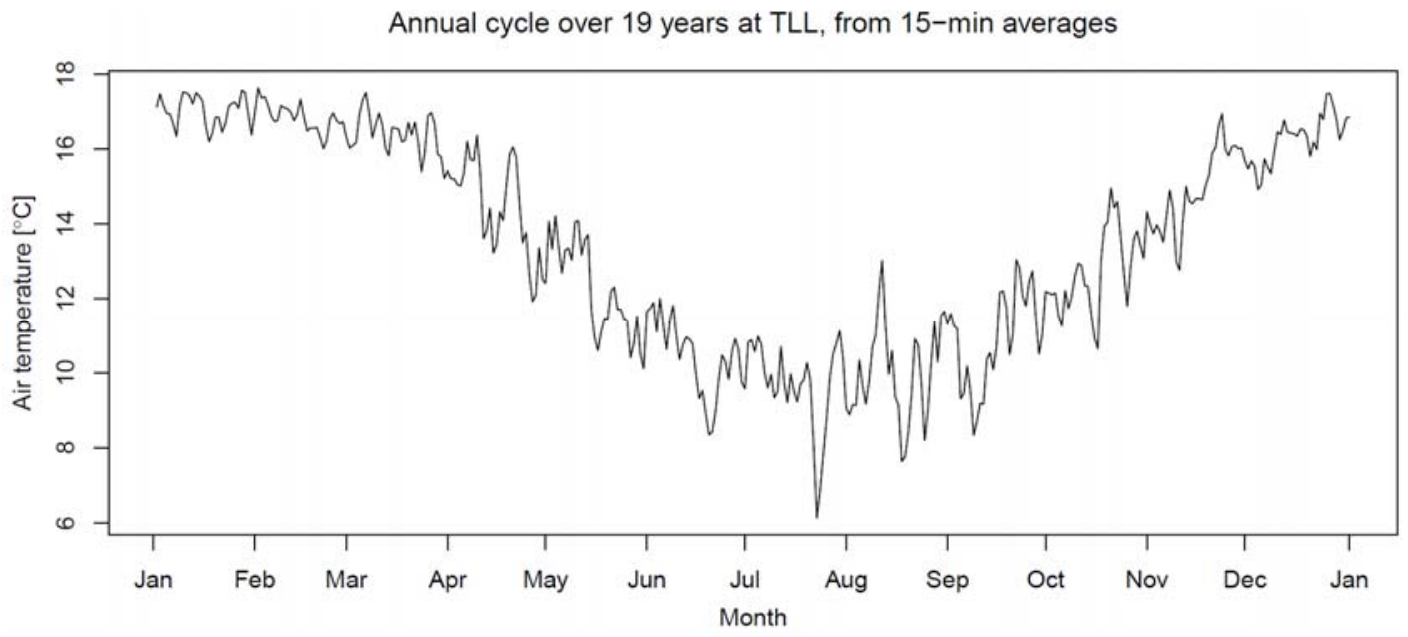

Fig. S3: Seasonal cycle of temperature over one year, computed as average over 19 years.

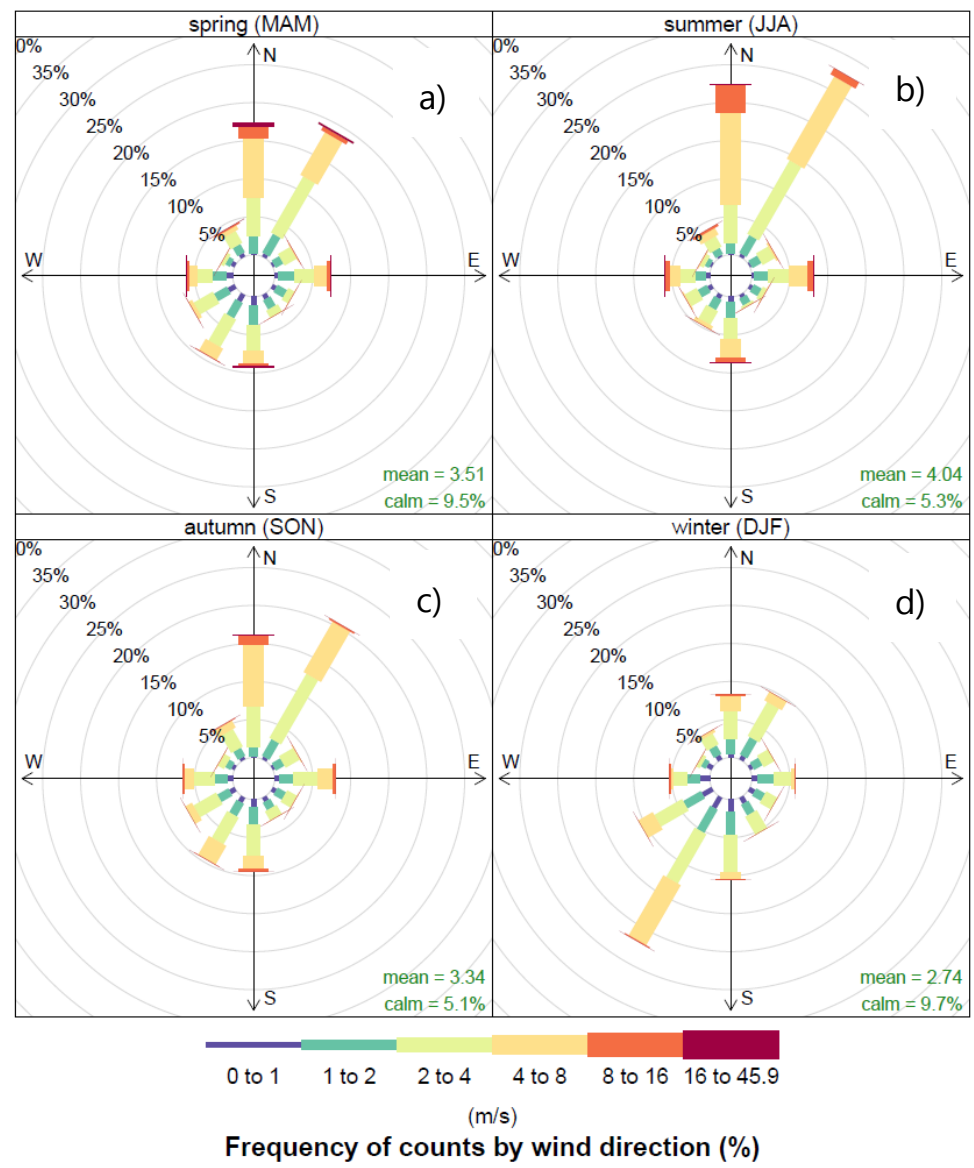

Fig. S4: Wind climatology 1995-2014 at El Tololo (DMC) for four seasons: (a) fall, (b) winter, (c) spring, (d) summer. 


\section{Starting altitude of trajectories}

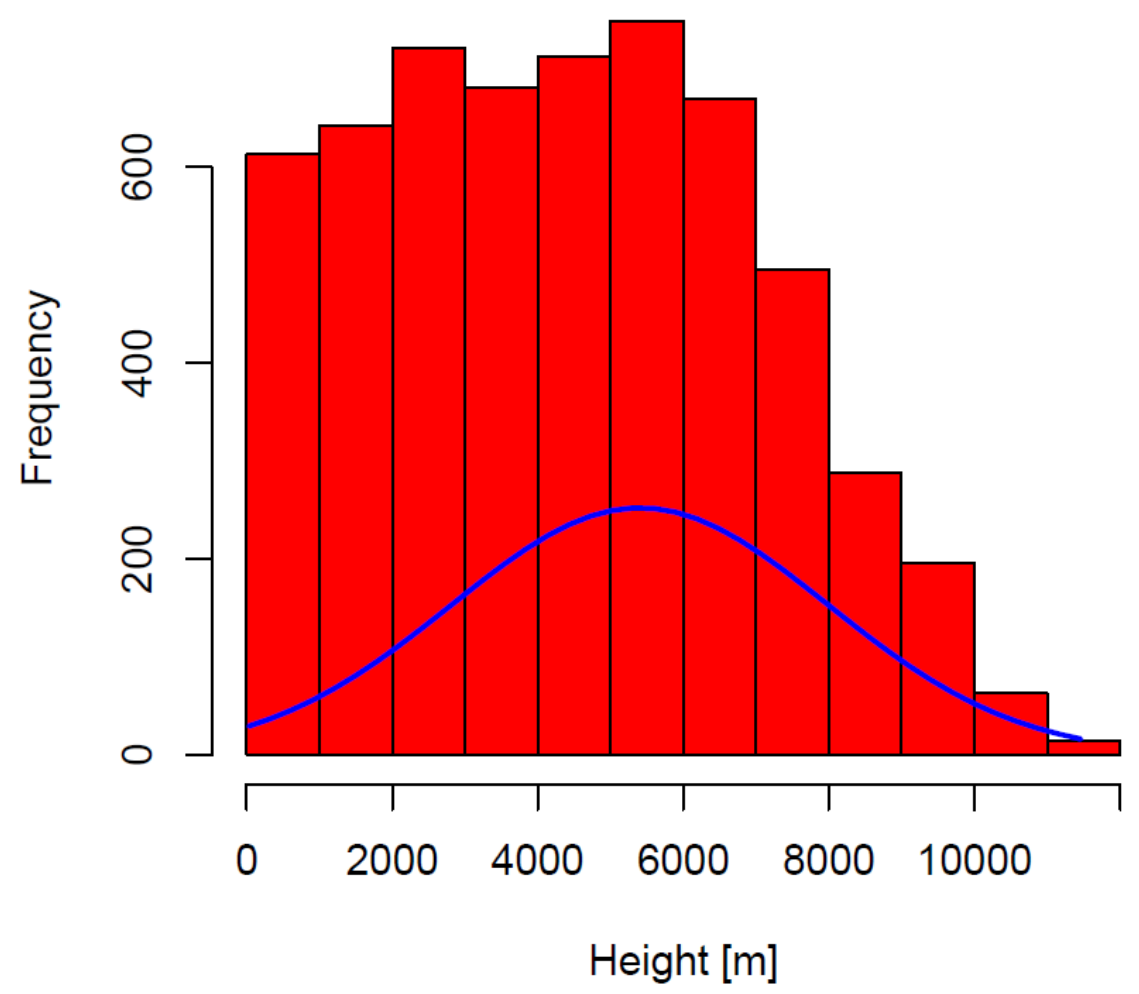

Fig. S5: Starting altitude distribution of the trajectories reaching TLL at a height of 370m. 

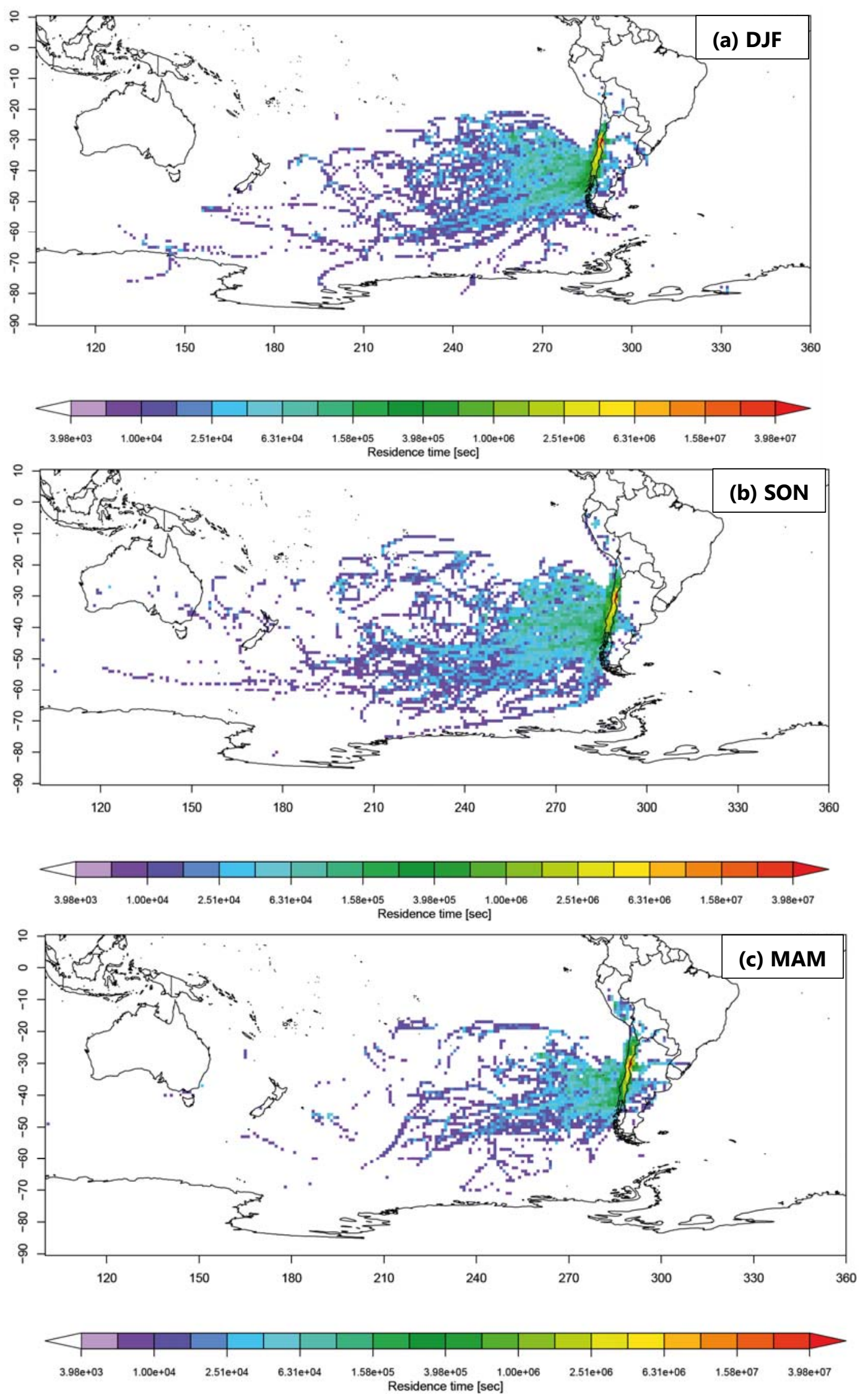


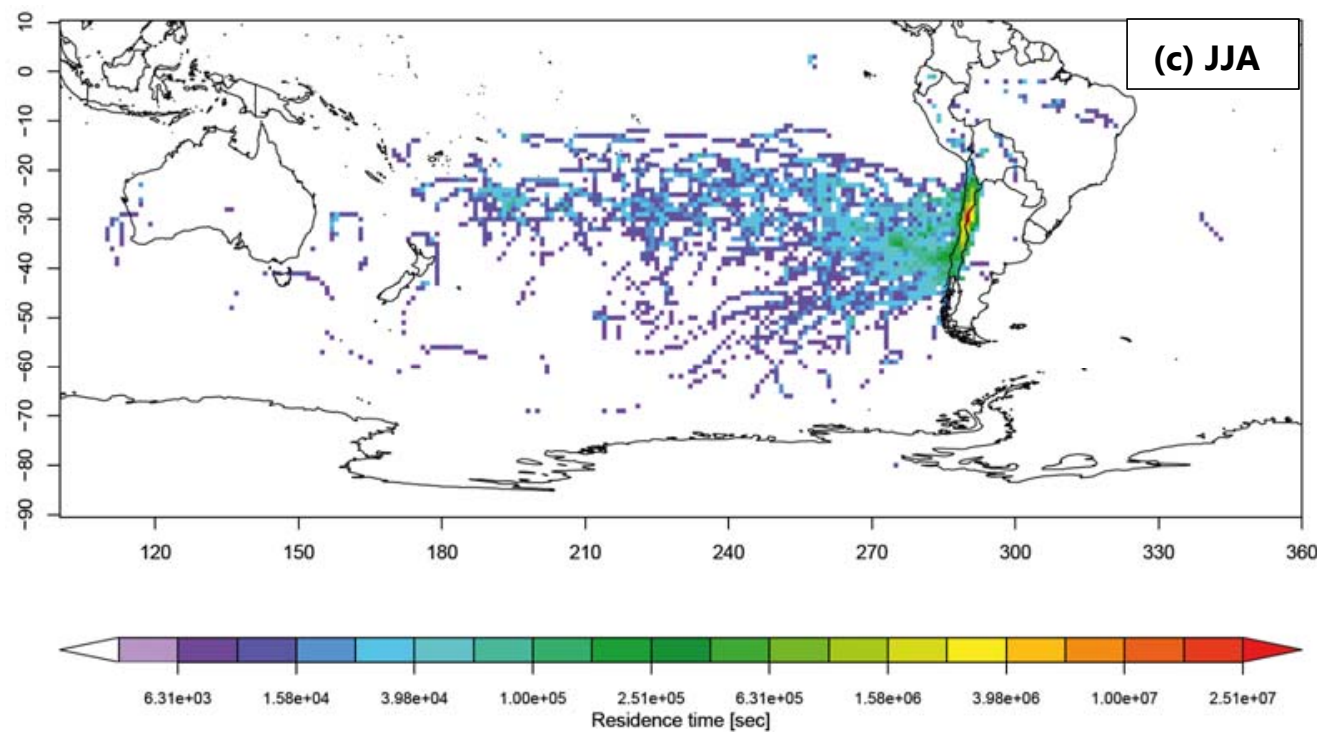

Fig. S6: FLEXTRA trajectory footprint from April 2013- December 2015, origin: TLL, 370m above model topography. Colour indicates the total residence time of air parcels, summed up over the time period. a) DJF, b) SON, c) MAM, d) JJA. 
Daily temperature data at El Tololo station

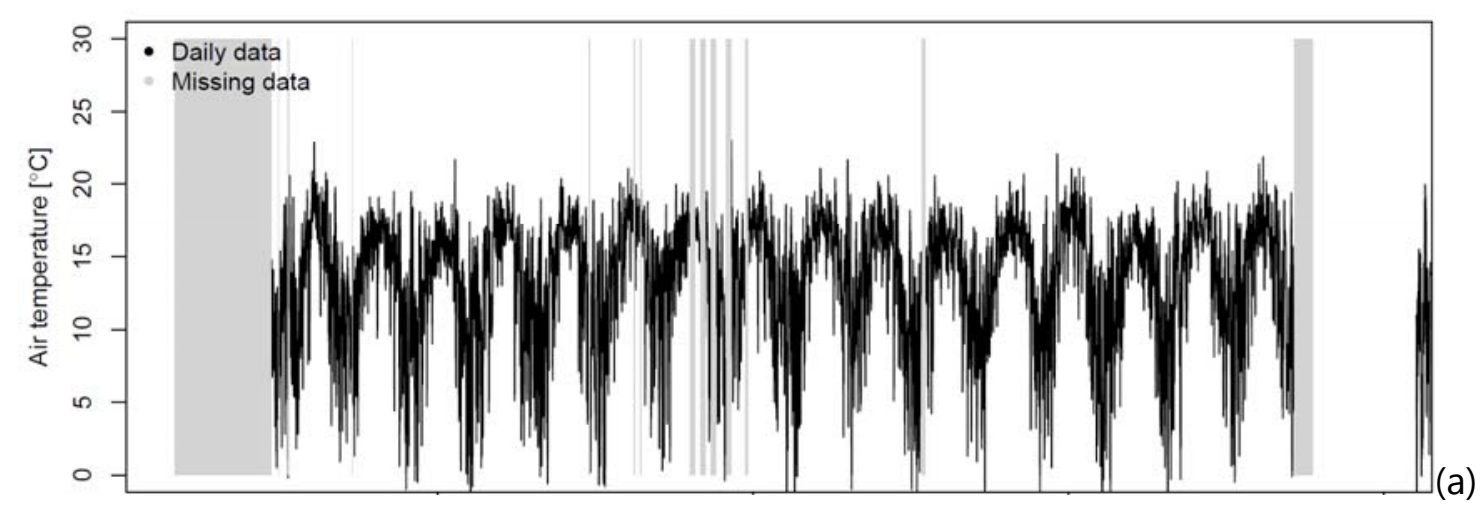

Daily QFE data at EI Tololo station

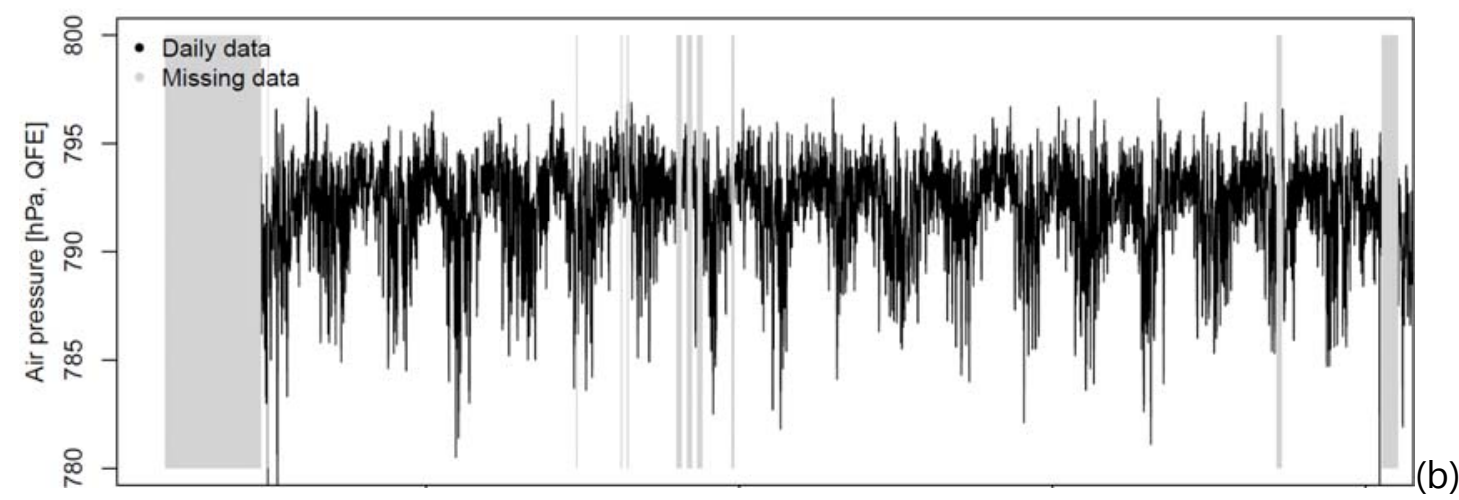

Daily relative humidity data at El Tololo station

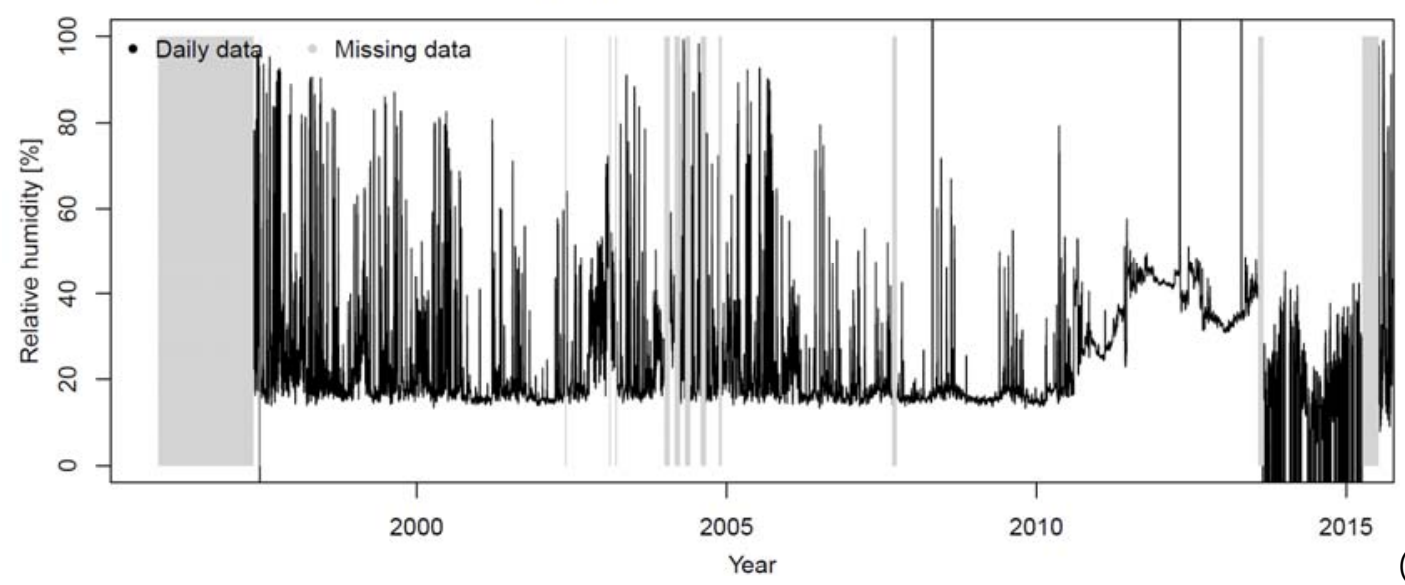

Fig. S7: Time series of a) air temperature, b) ambient pressure and c) relative humidity. Not available data is marked with grey lines. 


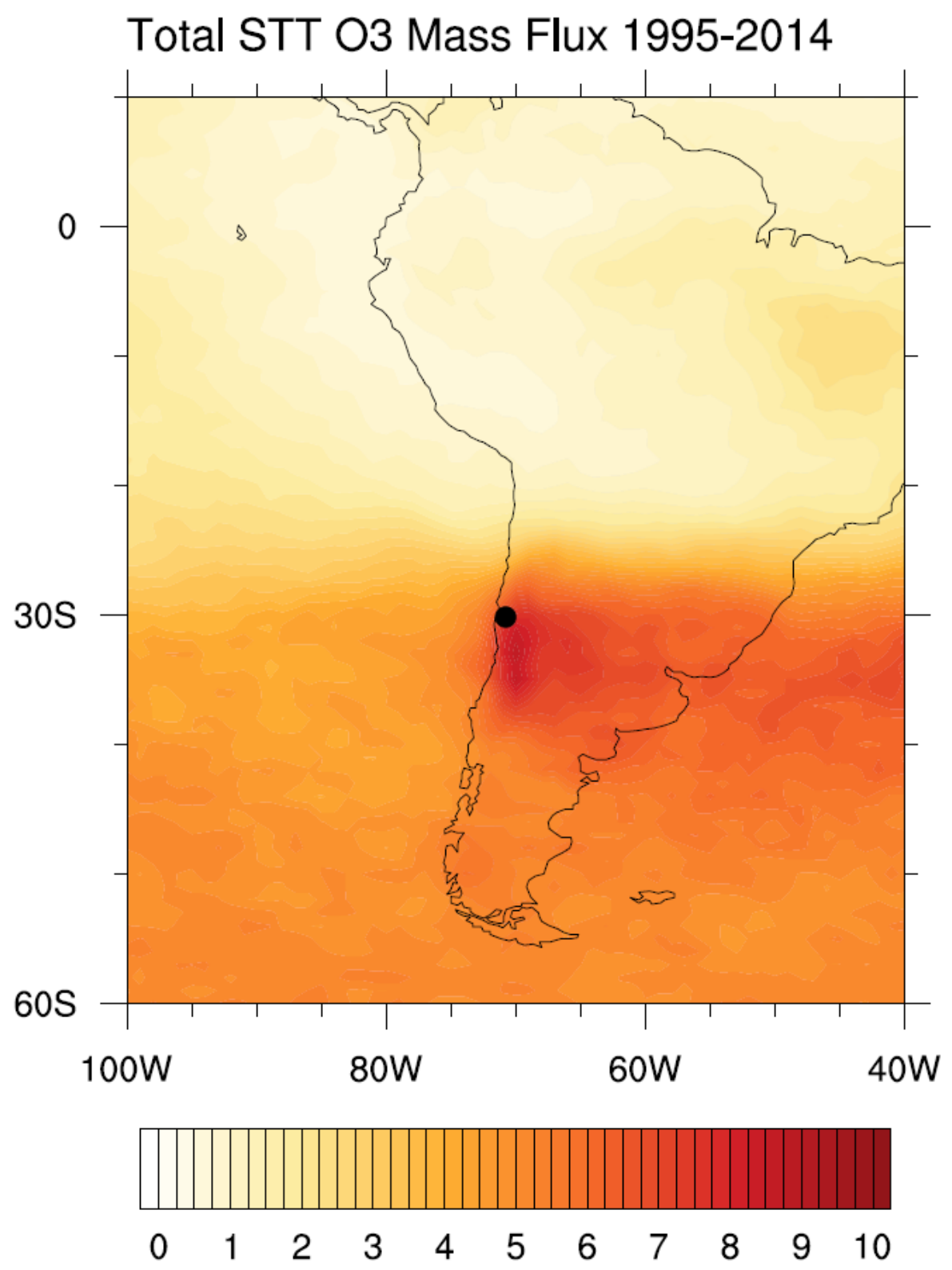

Fig. S8: Ozone Mass flux from the Stratosphere into the PBL, averaged from 1995 to 2014. 


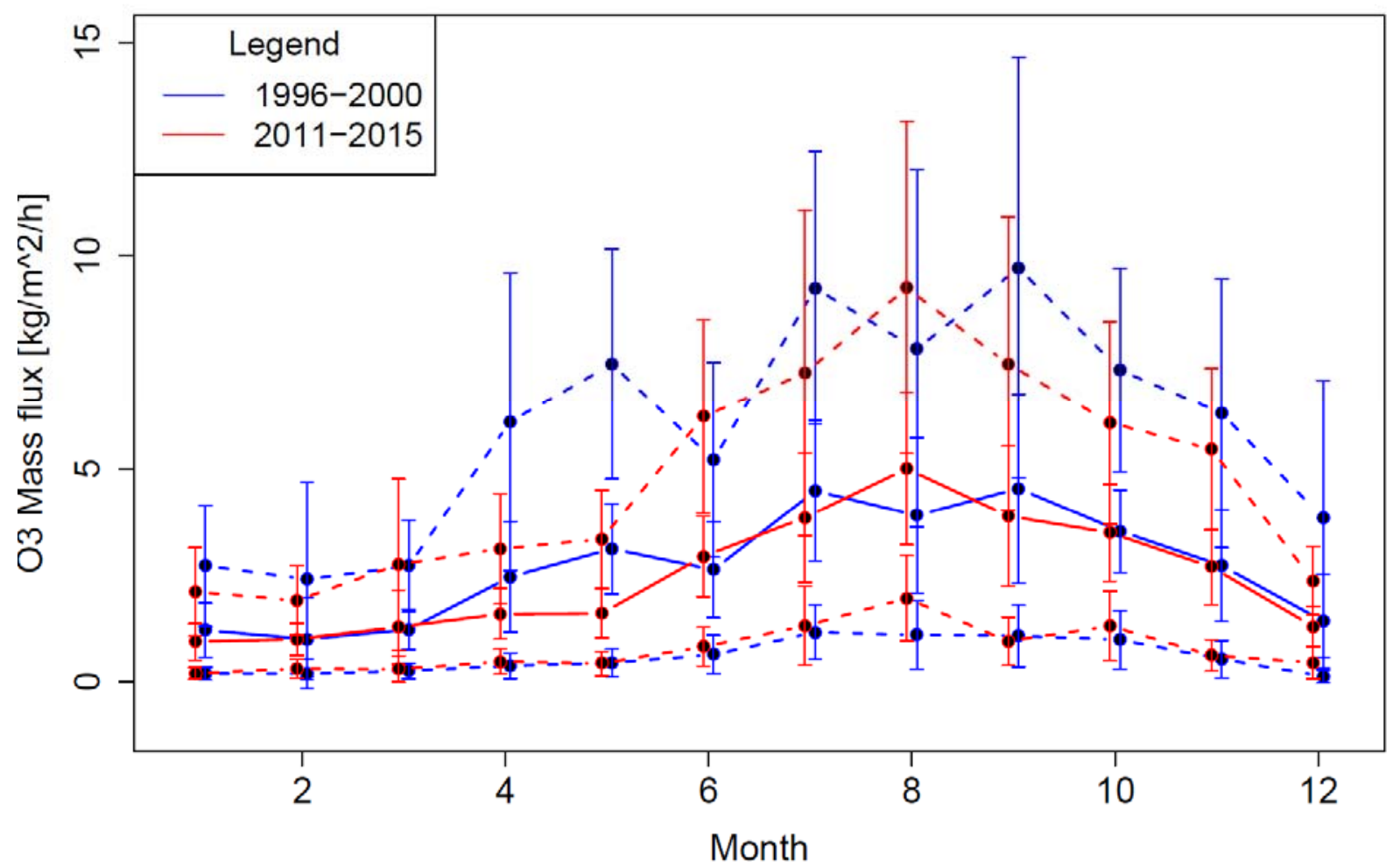

Fig. S9: Mean annual ozone STT mass flux cycle (1995-2000 and 2010-2015) showing mean, upper 95th percentile and lower 5 th percentile.

Table S1: List of documented extended data gaps and their reasons.

\begin{tabular}{ccl}
\hline Start of gap & End of gap & Reason \\
\hline 09.07 .1999 & 14.07 .1999 & Power outage, no UPS available \\
09.12 .1999 & 17.12 .1999 & Repainting of the measurement hut, data flagged. \\
12.08 .2000 & 25.08 .2000 & Power outage, no UPS available \\
27.09 .2001 & 10.10 .2001 & Internal pump failed \\
24.05 .2002 & 04.04 .2003 & Internal pump failed, equipment is sent to DMC and repaired \\
21.10 .2006 & 31.03 .2007 & Equipment is sent to Argentina for performance assessment (WCC-Empa) \\
03.09 .2010 & 02.10 .2010 & Equipment is shipped to DMC for maintenance \\
06.08 .2013 & 24.08 .2013 & Data logger failed \\
15.01 .2015 & 23.04 .2015 & Internal pump failed \\
23.04 .2015 & 19.06 .2015 & UV lamp failed \\
\hline
\end{tabular}

